\title{
Photofunctional Co-Cr Alloy Generating Reactive Oxygen Species for Photodynamic Applications
}

\author{
Kang-Kyun Wang, ${ }^{1}$ Bong-Jin Kim, ${ }^{1}$ Mi Hee Lee, ${ }^{2}$ Byeong-Ju Kwon, ${ }^{2,3}$ Dong Hoon Choi, ${ }^{4}$ \\ Jong-Chul Park, ${ }^{2,3}$ and Yong-Rok Kim ${ }^{1}$ \\ ${ }^{1}$ Department of Chemistry, Yonsei University, 50 Yonsei-ro, Seodaemun-Gu, Seoul 120-749, Republic of Korea \\ ${ }^{2}$ Cellbiocontrol Laboratory, Department of Medical Engineering, College of Medicine, Yonsei University, 250 Seongsanno, \\ Seodaemun-Gu, Seoul 120-752, Republic of Korea \\ ${ }^{3}$ Brain Korea 21 Project for Medical Science, College of Medicine, Yonsei University, Seoul 120-752, Republic of Korea \\ ${ }^{4}$ Cardiology Division, Cardiovascular Center, College of Medicine, Yonsei University, Seoul 120-752, Republic of Korea
}

Correspondence should be addressed to Jong-Chul Park; parkjc@yuhs.ac and Yong-Rok Kim; yrkim@yonsei.ac.kr

Received 6 December 2012; Revised 24 February 2013; Accepted 13 March 2013

Academic Editor: Maria da Graça P. Neves

Copyright (C) 2013 Kang-Kyun Wang et al. This is an open access article distributed under the Creative Commons Attribution License, which permits unrestricted use, distribution, and reproduction in any medium, provided the original work is properly cited.

\begin{abstract}
We report the fabrication of photofunctional Co-Cr alloy plate that is prepared by a simple modification process for photodynamic application. Photoinduced functionality is provided by the photosensitizer of hematoporphyrin $(\mathrm{Hp})$ that initially generates reactive oxygen species (ROS) such as superoxide anion radical and singlet oxygen. The photosensitizer with carboxyl group was chemically bonded to the surface of the Co-Cr alloy plate by esterification reaction. Microstructure and elemental composition of the Co-Cr alloy plate were checked with scanning electron microscopy (SEM) and energy dispersive X-ray spectrometer (EDS). Fabrication of the photofunctionality of the Co-Cr alloy plate was confirmed with X-ray photoelectron spectroscopy (XPS), reflectance UV-Vis absorption, and emission spectroscopy. Reactive oxygen generation from the photofunctional Co-Cr alloy plate was confirmed by using the decomposition reaction of 1,3-diphenylisobenzofuran (DPBF). The results suggest that the immobilized photosensitizer molecules on the surface of Co-Cr alloy plate still possess their optical and functional properties including reactive oxygen generation. To open the possibility for its application as a photodynamic material to biological system, the fabricated photofunctional Co-Cr alloy is applied to the decomposition of smooth muscle cells.
\end{abstract}

\section{Introduction}

Co-Cr alloy is a type of metallic alloy that has been used as a biomaterial for the human application. Co-Cr alloy is rapidly gaining attention for a wide variety of its applications in cardiology, orthopedics, and dentistry [1-5]. Compared with other metallic implant materials, Co-Cr alloy has several outstanding properties that make it attractive. It has good wear resistance, crevice corrosion resistance, and pitting resistance. It also has high abrasion resistance, fatigue strength along with good workability and ductility $[6,7]$. Due to such superior properties, Co-Cr alloy is currently used for coronary artery stents [8]. However, on the other hand, Co-Cr alloy stents are limited by the occurrence of restenosis induced by smooth muscle cell proliferation, neointimal hyperplasia, and thrombus formation [9-11]. To overcome the problems, polymer based drug eluting stents (DESs) were developed and reduced the occurrence of major cardiac event [12]. However, DES has also several drawbacks such as polymer fracture during stent expansion and inflammatory reaction to the polymer, which leads back to restenosis. Moreover, it is not easy to have precise control on the releasing rate of the drug, inducing problematic side effects [13-15]. DES also loses its functionality because of a limited amount of the drug included. Therefore, in a field of DES, a new semipermanent biomaterial that does not have side effect and cytotoxicity is in a great demand for the development. Furthermore, it must have the control function for the rate and time of drug elution.

In recent years, it has been reported that suppression of smooth muscle cells proliferation and destruction of 


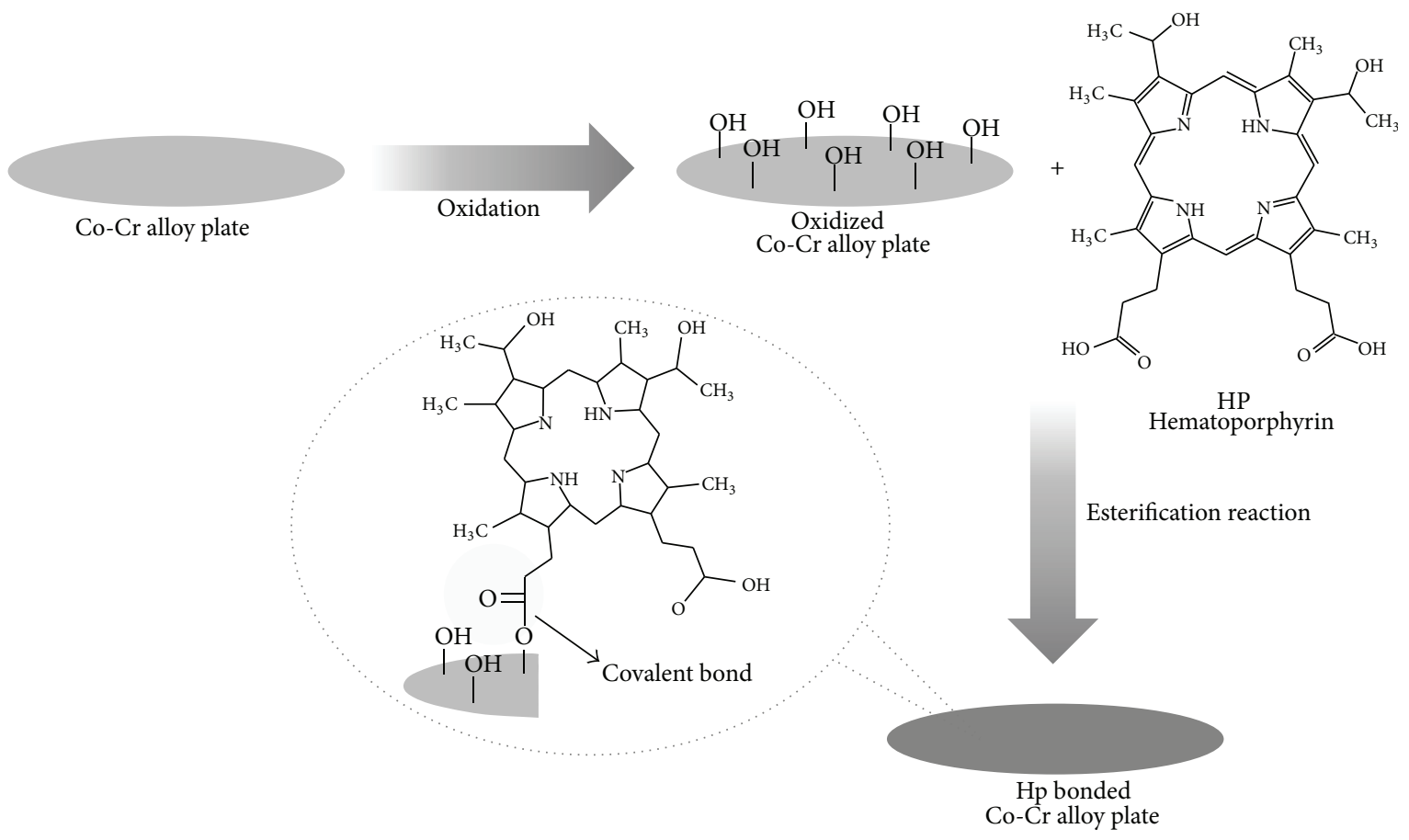

SCHeme 1: Fabrication procedure of the photofunctional Co-Cr alloy plate.

thrombus, the major factors for the control of restenosis, are achieved by reactive oxygen generated from photodynamic inactivation $[16,17]$. In details, the photosensitizer hematoporphyrin $(\mathrm{Hp})$ in its ground state absorbs light and undergoes intersystem crossing (ISC) with high efficiency to its triplet state. Then the reactive oxygen species (ROS) can be generated from the triplet state of photosensitizer by energy transfer or charge transfer processes [18]. Photodynamic inactivation for therapy has been applied for many years and it is now becoming widely accepted and utilized. Photodynamic therapy (PDT) can be defined as a therapy that involves the administration of a nontoxic drug or dye known as a photosensitizer (PS) either systemically, locally, or topically to a patient bearing a lesion, which is frequently, but not always used for cancer treatment [18]. After an incubation period, the specific lesion is then usually illuminated with a visible light in the presence of oxygen, which leads to the generation of cytotoxic species of reactive oxygen and consequently causes cell death and tissue devastation [19, 20]. The use of reactive oxygen species (ROS) in PDT is particularly attractive because of its high efficiency for deactivation of harmful organism and with less side effect. Therefore, ROS can be applied in water disinfection, air cleaning, and thrombolysis [21-23].

In this study, we have successfully fabricated the photofunctional Co-Cr alloy plate by a simple process. Photoinduced functionality of the fabricated photofunctional Co-Cr alloy plate is provided by the photosensitizer of hematoporphyrin (Hp) that can generate reactive oxygen species (ROS) such as superoxide anion radical and/or singlet oxygen. The generation efficiency of ROS from the fabricated photofunctional Co-Cr alloy plate is confirmed with photocatalytic experiment. Furthermore, photodynamic inactivation of cells by the photofunctional $\mathrm{Co}-\mathrm{Cr}$ alloy plate is investigated with rat aorta smooth muscle cells (RAOSMCs) for the potential bioapplication.

\section{Experimental}

2.1. Preparation of the Photofunctional Co-Cr Alloy Plate. Overall synthetic procedure of the photofunctional $\mathrm{Co}-\mathrm{Cr}$ alloy plate is presented in Scheme 1. Hematoporphyrin (Hp, Aldrich) was used as a photosensitizer. All solvents from Merk were used without further purification. Co-Cr alloy plate (Tae-woong medical, $5 \times 3 \times 0.2 \mathrm{~mm}$ ) was washed and sonicated with acetone for $30 \mathrm{~min}$. It was then dipped into piranha solution $\left(\mathrm{H}_{2} \mathrm{O}_{2}: \mathrm{H}_{2} \mathrm{SO}_{4}=1: 3(\mathrm{vol} \%)\right)$ for $2 \mathrm{~h}$ at $100^{\circ} \mathrm{C}$. To enhance the hydroxyl groups on the surface of Co-Cr alloy plate, the oxidized Co-Cr alloy plate was immersed in boiling $\mathrm{H}_{2} \mathrm{O}_{2}$ solution for $50 \mathrm{~min}$. The fully oxidized $\mathrm{Co}-\mathrm{Cr}$ alloy plate was reacted with Hp/ethanol solution in the presence of EDC/NHS (wt\%, 1:1) for $3 \mathrm{~h}$ at room temperature. Finally, it was washed with ethanol and then dried. The washing solution and reactant solution were collected and measured with UV-Vis spectrophotometer for the quantization of $\mathrm{Hp}$ bonded to the surface of the oxidized $\mathrm{Co}-\mathrm{Cr}$ alloy plate. Amount of $\mathrm{Hp}$ bonded to the surface of the oxidized $\mathrm{Co}-\mathrm{Cr}$ alloy plate was estimated to be $1.1 \times$ $10^{-8} \mathrm{~mol} / \mathrm{cm}^{2}$.

2.2. Characterization of the Photofunctional Co-Cr Alloy Plate. Surface morphology and elemental composition of the Co$\mathrm{Cr}$ alloy plate were observed by field emission scanning electron microscopy (FE-SEM, Hitachi, SU-70) equipped 


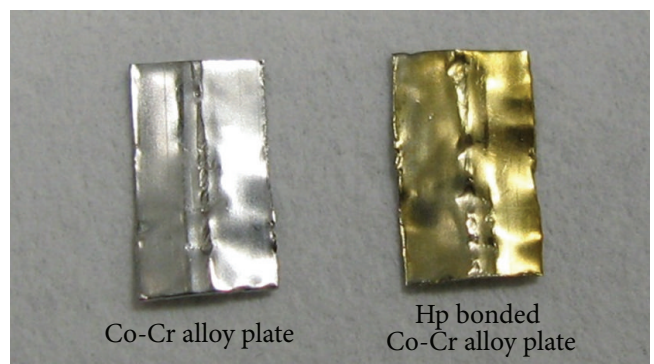

(a)

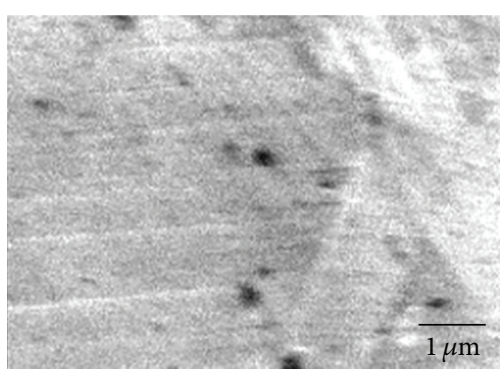

(b)
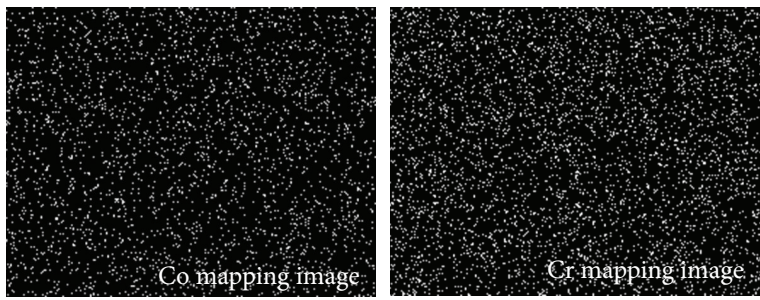

(c)

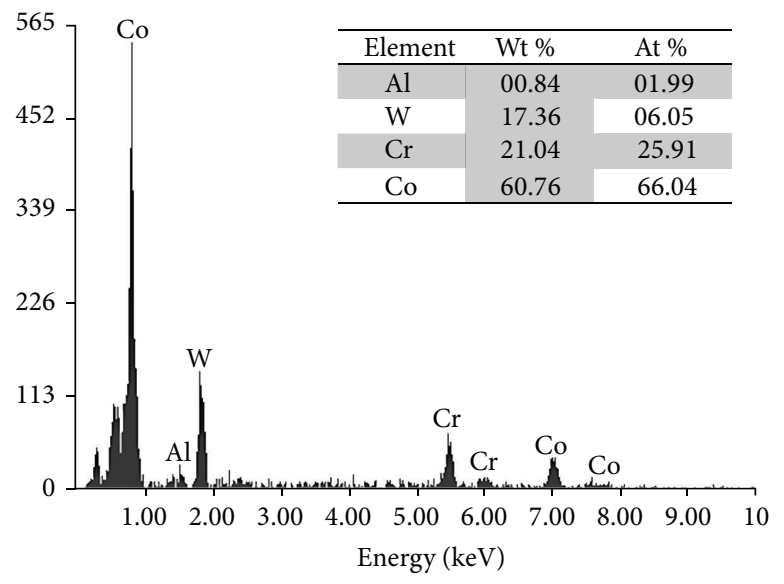

(d)

Figure 1: (a) Photograph, (b) FE-SEM image, (c) EDS mapping images, and (d) elemental analysis of Co-Cr alloy plate.

with an energy dispersive X-ray spectroscopy (EDS). The functional groups on the surface of the Co-Cr alloy plate were confirmed with X-ray photoelectron spectroscopy (XPS, Thermo VG, Escalab 220i-XL). XPS was used to determine the atomic composition of the sample surface. Compositional survey and detailed scans were acquired using pass energy of $50 \mathrm{eV}$. The binding energies were corrected by referencing the $\mathrm{C}$ 1s binding energy to $285 \mathrm{eV}$. Steady-state absorption and emission spectra were obtained with a diffuse reflectance UV-Vis spectrophotometer (Jasco V-550) equipped with an integrating sphere (Jasco ISV-469) and a spectrofluorimeter (Hitachi, F-4500), respectively.

2.3. Detection of Reactive Oxygen Generation from the Photofunctional Co-Cr Alloy Plate. Degradation of 1,3diphenylisobenzofuran (DPBF), a reactive oxygen quencher [24], was studied with the photofunctional Co-Cr alloy plate. In a typical experiment, $3.5 \mathrm{~mL}$ of EtOH solution containing the photofunctional Co-Cr alloy plate and DPBF $\left(1.0 \times 10^{-5} \mathrm{M}\right)$ was introduced into a $1 \mathrm{~cm}$ quartz cell in the dark. The light source for irradiation photofunctional Co$\mathrm{Cr}$ alloy plate was a nanosecond Nd-YAG pumped optical parametric oscillator (OPO) laser (OPOLETT, $20 \mathrm{~Hz}, 5 \mathrm{~ns}$ FWHM pulse). The total output power for the irradiation was measured with a laser power meter (Ophir-optronics Ltd., Nova, 10A-P-V2-SH), and the irradiated laser power was $15 \mathrm{~mW}$ at $510 \mathrm{~nm}$. At every $10 \mathrm{~min}$ of irradiation, the absorption spectra of the DPBF were monitored with a UVVis spectrophotometer (Hitachi, U-2800).

\subsection{The Photodynamic Inactivation of Cells by ROS Generated} from the Photofunctional Co-Cr Alloy Plate. To evaluate the photodynamic inactivation efficacy of the photofunctional Co-Cr alloy plate, rat aorta smooth muscle cells (RAOSMC, biobud, Korea) were used. Rat aorta smooth muscle cells were cultured in Dulbecco's modified Eagle's medium (DMEM, Wellgene, Korea) supplemented with $10 \%$ fetal bovine serum (FBS, Wellgene) and $1 \%$ antibiotic antimitotic solution (including 10,000 $\mathrm{U}$ penicillin, $10 \mathrm{mg}$ streptomycin, and $25 \mu \mathrm{g}$ amphotericin $\mathrm{B}$ per $\mathrm{mL}$, Wellgene) at $37^{\circ} \mathrm{C}$ and $5 \% \mathrm{CO}_{2}$ in a humid environment. Studies were performed with the cells between passages 5 and 9. For the experiment, the photofunctional Co-Cr alloy plate was sterilized by using $70 \%$ $\mathrm{EtOH}$ for $30 \mathrm{~min}$ and washed twice with phosphate buffered saline (PBS). Then, RAOSMCs were seeded at a density of $5 \times$ $10^{4} / \mathrm{cm}^{2}$ on photofunctional Co-Cr alloy plate and incubated for $24 \mathrm{~h}$. For photodynamic inactivation (PDI) of RAOSMC, the laser light $(510 \mathrm{~nm}, 15 \mathrm{~mW})$ is irradiated to RAOSMC on photofunctional Co-Cr alloy plate for $15 / 30 \mathrm{~min}$ at $37^{\circ} \mathrm{C}$. After irradiation, the samples were washed with $\mathrm{PBS}$ and fixed in $70 \% \mathrm{EtOH}$ overnight at $-20^{\circ} \mathrm{C}$. Following fixation, the cells were stained with Texas Red C2-maleimide $(5 \mathrm{U} / \mathrm{mL}$, invitrogen) and Alexa 488-conjugated rhodamine phalloidin (5 $\mathrm{U} / \mathrm{mL}$, invitrogen) to visualize plasma membrane, and 


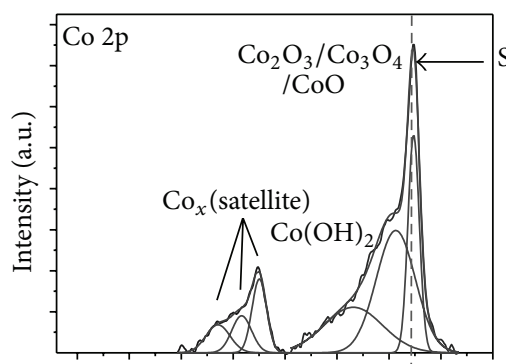

$\begin{array}{llllll}810 & 805800795790785780 & 775 & 770\end{array}$

Binding energy $(\mathrm{eV})$

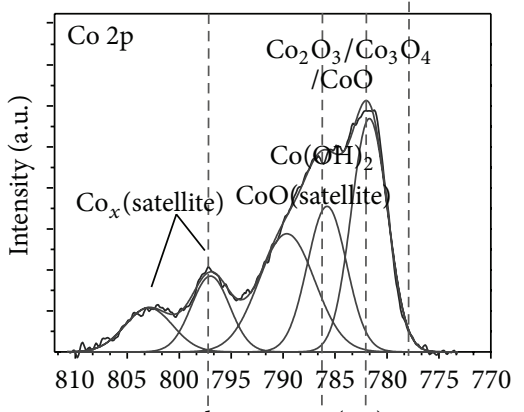

Binding energy $(\mathrm{eY})$

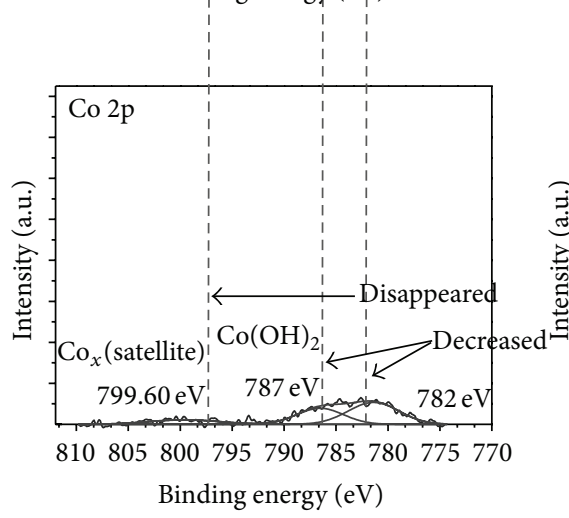

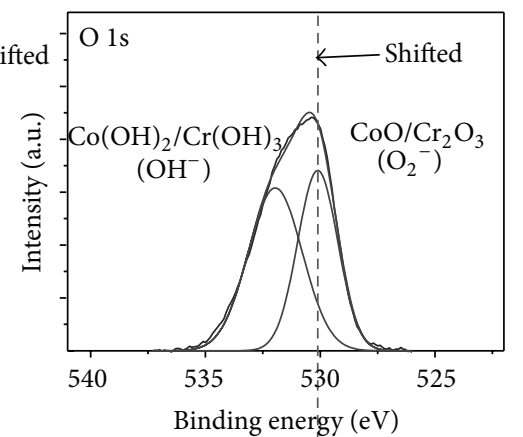

(a)

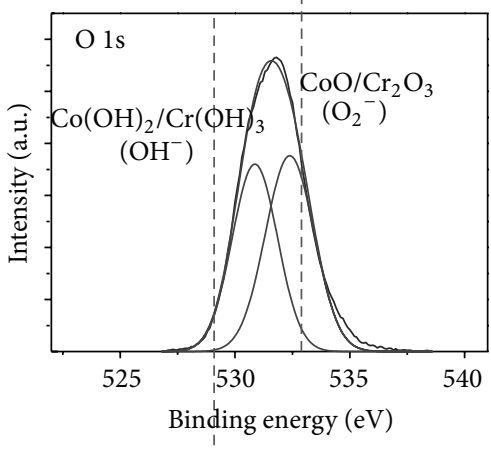

(b)

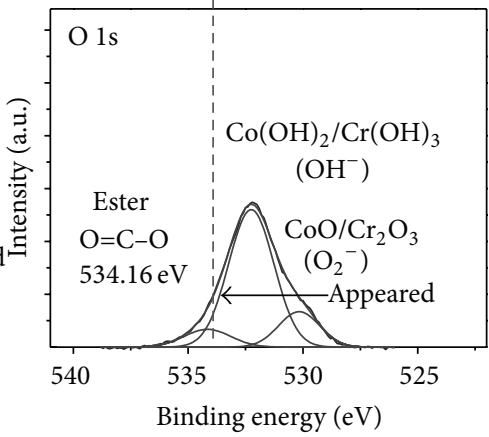

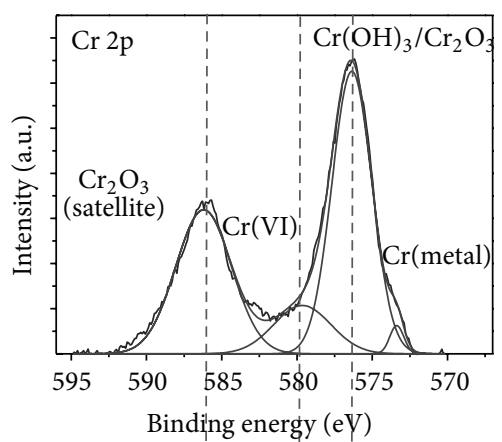
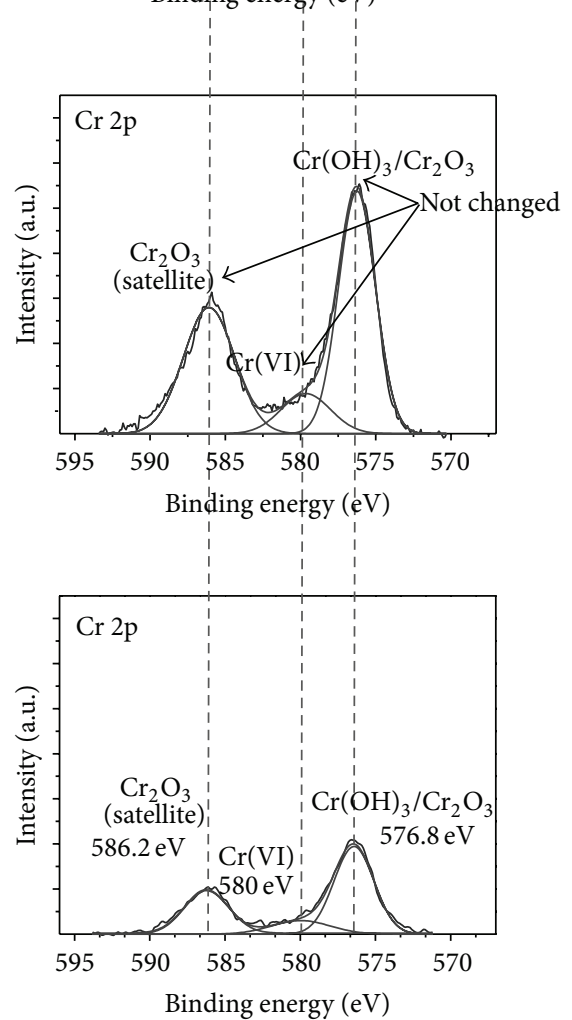

(c)

Figure 2: XPS analysis of (a) the pure Co-Cr alloy plate, (b) the oxidized Co-Cr alloy plate, and (c) the Hp bonded Co-Cr alloy plate.

cytoskeleton and nuclei were counterstained with Hoechst 33528. The morphological observation of RAOSMC was evaluated using an Olympus fluorescence microscope (Melville, NY) equipped with a DP-71 digital camera (Olympus, Japan).

\section{Results and Discussion}

The color of Co-Cr alloy plate is changed when hematoporphyrin is introduced to surface of the oxidized $\mathrm{Co}-\mathrm{Cr}$ alloy plate as shown in Figure 1(a). Figure 1(c) shows that the surface of the Co-Cr alloy plate is homogeneously composed of $\mathrm{Co}$ and $\mathrm{Cr}$ elements. Also, surface of the Co-Cr alloy plate is almost consisted of Co (66\%) and Cr (26\%) as shown in Figure 1(d). X-ray photoelectron spectroscopy (XPS) gives a detailed elemental composition of the surface. Figure 2 presents the XPS spectra over the binding energy range of 278-810 eV for (a) the pure Co-Cr alloy plate, (b) the oxidized
Co-Cr alloy plate, and (c) the Hp bonded Co-Cr alloy plate. The spectra indicate the characteristic peaks corresponding to $\mathrm{Co}, \mathrm{Cr}$, and $\mathrm{O}$ that exist in $\mathrm{Co}-\mathrm{Cr}$ alloy plate. The binding energies of $\mathrm{O} 1 \mathrm{~s}$ and $\mathrm{Co} 2 \mathrm{p}$ for the oxidized Co-Cr alloy plate are slightly shifted to higher energy than the pure Co-Cr alloy plate. The peaks of Co $2 \mathrm{p}$ at 799.6, 787.0, and $782.0 \mathrm{eV}$ for the Hp bonded Co-Cr alloy plate are almost disappeared or significantly decreased and the ester peak of $\mathrm{O}$ 1s for the $\mathrm{Hp}$ bonded Co-Cr alloy plate is appeared at $534.2 \mathrm{eV}$. In more details, the peak at $534.2 \mathrm{eV}$ is attributed to the presence of $\mathrm{C}=\mathrm{O}$ and $\mathrm{O}=\mathrm{C}-\mathrm{O}$ that resulted from the esterification reaction between the hydroxyl group on surface of the oxidized Co-Cr alloy plate and the carboxylic acid group of Hp. The peaks of Co $2 \mathrm{p}$ at 799.6, 787.0, and $782.0 \mathrm{eV}$ are disappeared or decreased due to the esterification reaction between Co and $\mathrm{Hp}$. attributed to oxidation potential of Co $2 \mathrm{p}$. On the other hand, the peaks of $\mathrm{Cr} 2 \mathrm{p}$ for pure $\mathrm{Co}-\mathrm{Cr}$ 


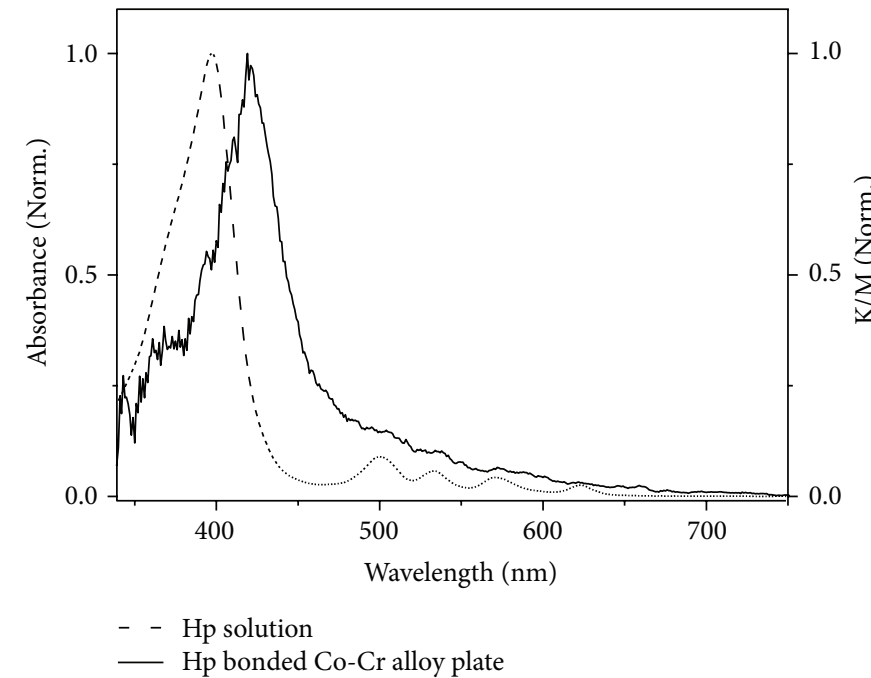

(a)

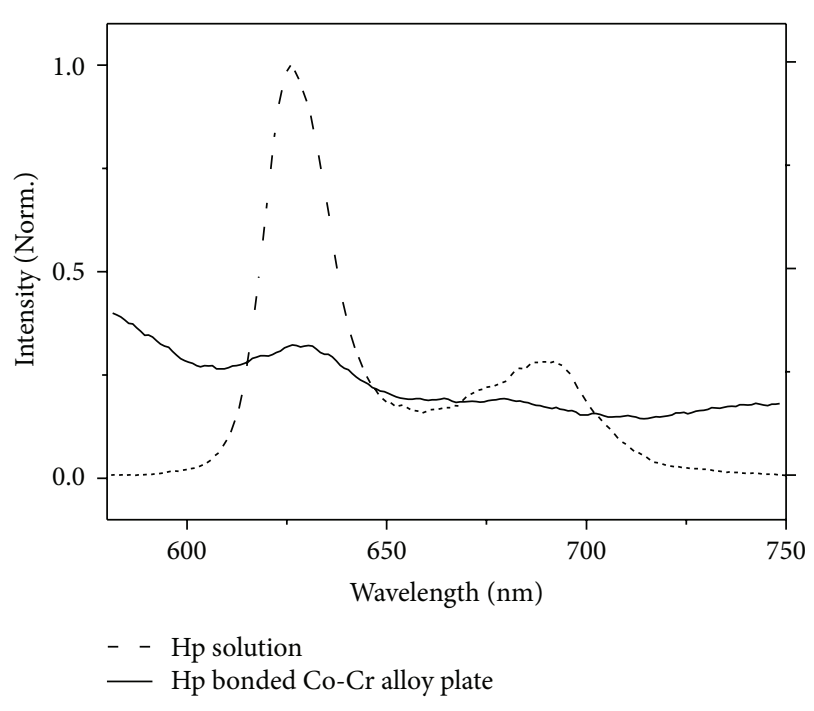

(b)

FIgURE 3: (a) Absorption and (b) emission spectra of $\mathrm{Hp}$ in EtOH (dashed line) and of the Hp bonded to Co-Cr alloy plate (solid line).

alloy plate are observed at $576.8,580.0$, and $586.2 \mathrm{eV}$ and these peaks are not changed when the pure Co-Cr alloy plate is oxidized and $\mathrm{Hp}$ is bonded to the surface of $\mathrm{Co}-\mathrm{Cr}$ alloy plate as shown in Figure 2. It means that $\mathrm{Hp}$ is dominantly bonded to Co elements. Such tendency is in a good agreement with the reported values of the oxidized Co-Cr alloy and other organic compounds bonded Co-Cr alloy [25-27].

Diffuse reflectance UV-Vis absorption spectrum of the photofunctional Co-Cr alloy plate is presented in Figure 3(a) along with the absorption spectrum of the pure Hp molecules in an ethanol solution. Diffuse reflectance spectrum is a type of the absorption spectrum measured by the scattering from the surface of the sample. This diffuse reflectance spectrum is translated into the absorption spectra by the Kubelka-Munk method as follows:

$$
\frac{K}{S}=\frac{(1-R)^{2}}{2 R}
$$

where $K$ indicates the absorption coefficient, and $S$ and $R$ represent the scattering coefficient and the absolute reflectance, respectively [28].

The spectrum of Hp solution shows a B band $(413 \mathrm{~nm})$ and four Q bands $(500,531,572,622 \mathrm{~nm})$. Diffuse reflectance absorption spectrum of the photofunctional Co-Cr alloy plate also presents B and Q bands at the similar wavelengths but with broad shape and slightly red shifted peak position. The difference in the peak width and position is possibly due to the self-coupling of $\mathrm{Hp}$ molecules bonded to the surface and the inhomogeneous bonding nature of $\mathrm{Hp}$ molecules on the surface of Co-Cr alloy plate. The fluorescence spectrum of Hp $\left(\lambda_{\text {ex }}=510 \mathrm{~nm}\right)$ solution in Figure 3(b) presents the peaks at $660 \mathrm{~nm}$ and $725 \mathrm{~nm}$, and the photofunctional Co$\mathrm{Cr}$ alloy plate shows the fluorescence spectrum with a similar red shift due to the same nature for the excited state of the $\mathrm{Hp}$ molecules bonded to $\mathrm{Co}-\mathrm{Cr}$ alloy plate as in the

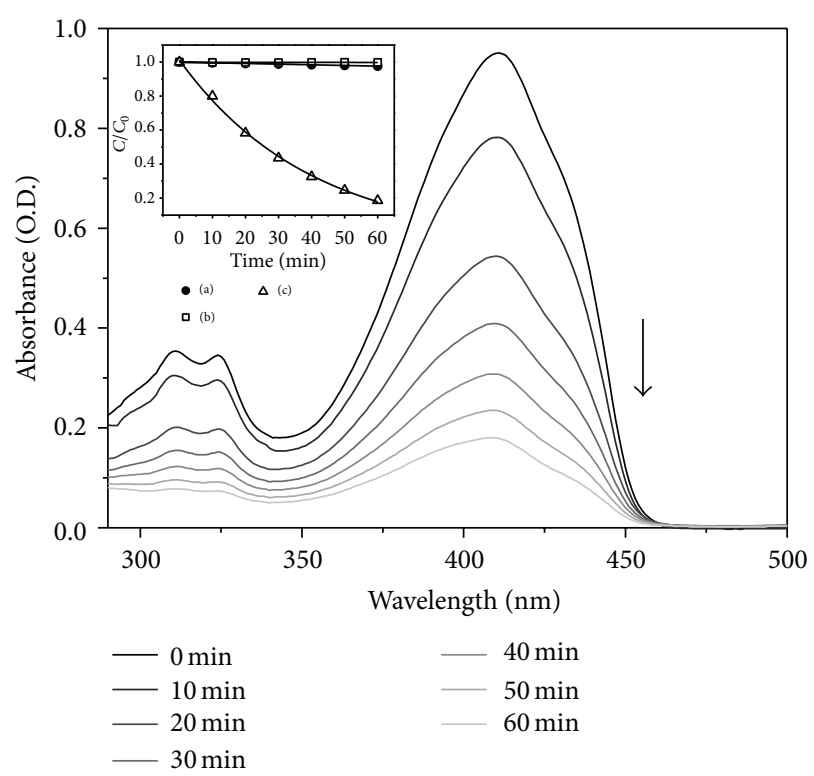

FIgURE 4: Reaction time dependent UV-Vis spectra of DPBF in the presence of the photofunctional $\mathrm{Co}-\mathrm{Cr}$ alloy plate in $\mathrm{EtOH}$ solution with a $510 \mathrm{~nm}$ laser irradiation. The inset represents the ratio between the after decomposition reaction O.D. $(C)$ and the initial O.D. $\left(C_{0}\right)$ of DPBF as function of irradiation time: (a) DPBF only under the light, (b) DPBF with the photofunctional Co-Cr alloy plate in the dark condition, (c) DPBF with the photofunctional Co$\mathrm{Cr}$ alloy plate under the light.

ground states [29-31]. Therefore, the results suggest that $\mathrm{Hp}$ molecules are bonded to the surface of $\mathrm{Co}-\mathrm{Cr}$ alloy through the esterification reaction without a significant change of its photophysical properties.

Decomposition study of DPBF was performed with the photofunctional Co-Cr alloy plate that generates ROS upon 


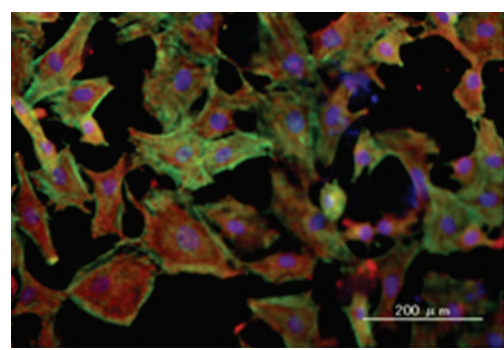

(a)

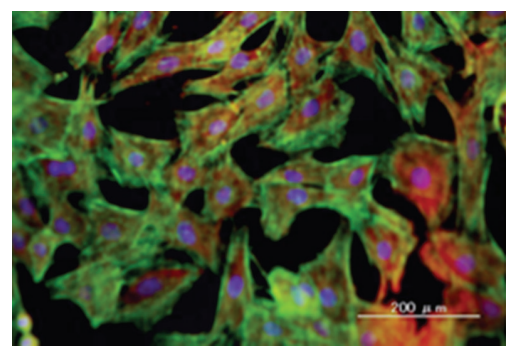

(d)

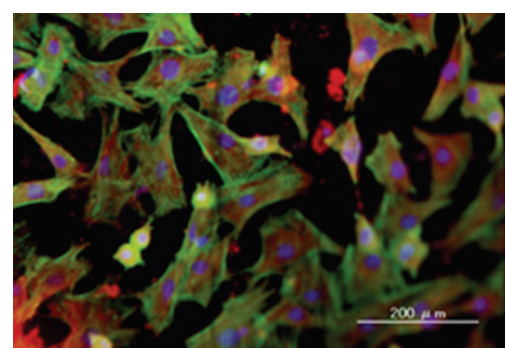

(b)

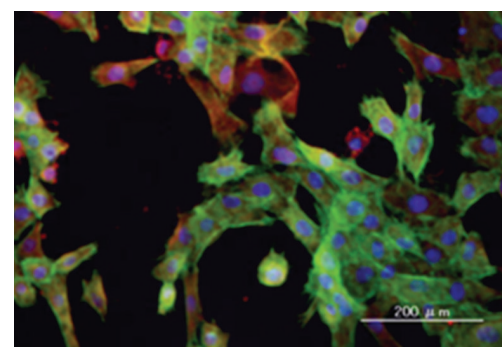

(e)

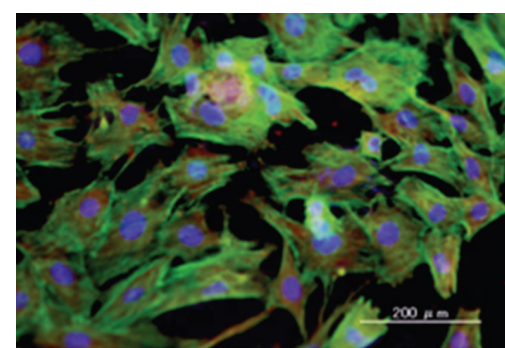

(c)

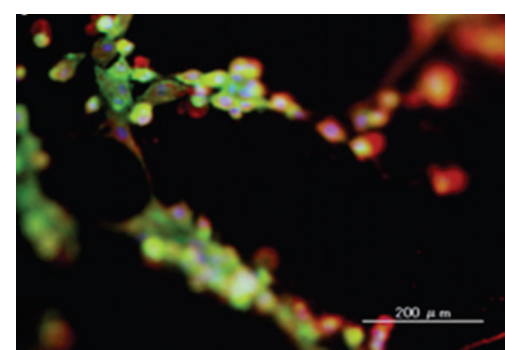

(f)

FIgure 5: Morphology of RAOSMC on the pure Co-Cr alloy plate $(\mathrm{a}-\mathrm{c})$ and the photofunctional Co-Cr alloy plate (d-f) without laser irradiation ( $a, d$ ) and with laser irradiation for $15 \mathrm{~min}(\mathrm{~b}, \mathrm{e})$ and $30 \mathrm{~min}(\mathrm{c}, \mathrm{f})$ of $15 \mathrm{~mW} / \mathrm{cm}^{2}\left(\lambda_{\mathrm{ex}}=510 \mathrm{~nm}\right)$. Green, red, and blue represent cytoskeleton, plasma membrane, and nuclei, respectively. Magnification was 200x.

irradiation. As a ROS quencher, DPBF readily undergoes 1,4-cycloaddition reaction with singlet oxygen to form an endoperoxide that decomposes into the irreversible product (1,2-dibenzoylbenzene) [24]. It is also reported that DPBF can be decomposed by superoxide anion radical of ROS $[32,33]$. As shown in the inset of Figure 4, the optical densities of DPBF absorption peak at $415 \mathrm{~nm}$ are not changed by the irradiation of light and, also, by the photofunctional Co-Cr alloy without the light irradiation condition. Therefore, the decomposition rate induces the decrease of the optical density of the DPBF absorption peak at $415 \mathrm{~nm}$ as shown in Figure 4, which indicates the generation of ROS from the photoirradiated surface of the photofunctional Co-Cr alloy plate.

Figure 5 shows the fluorescence microscope image for the comparative morphologies of the cells after laser irradiation on the photofunctional Co-Cr alloy plate by fluorescence microscope. RAOSMC had well organized plasma membrane (Red) and the actin cytoskeleton (Green) on the pure Co-Cr alloy plate. The morphology of the cells on the pure $\mathrm{Co}-\mathrm{Cr}$ alloy plate was not changed even with the laser irradiation compared to the nontreated cells (Figures 5(a)-5(c)). Also, the morphology of the cells on the photofunctional Co-Cr alloy plate was not changed in the dark condition. However, the cells appeared loosely to be adherent and lost their normal morphology after laser irradiation of $15 \mathrm{~mW} / \mathrm{cm}^{2}$ for $15 \mathrm{~min}$ on the photofunctional Co-Cr alloy plate (Figure 5(e)). Also, the cells get rounded and detached from the surface with the irradiation of $30 \mathrm{~min}$ (Figure 5(f)). These results reveal that the cells are damaged by ROS from the photo-irradiated surface of the photofunctional Co-Cr alloy plate upon irradiation of light $[34,35]$.

\section{Conclusion}

The photofunctional Co-Cr alloy plate is successfully fabricated by a simple surface modification process of oxidation and esterification reaction with $\mathrm{Hp}$. The surface of the $\mathrm{Co}-\mathrm{Cr}$ alloy plate homogeneously consists of $\mathrm{Co}$ and $\mathrm{Cr}$ elements. The X-ray photoelectron, UV-Vis, and emission spectra indicate that the Hp molecules are covalently bonded to the surface of the Co-Cr alloy plate through the carboxyl group. The DPBF decomposition study indicates that ROS is efficiently generated from the photoexcited $\mathrm{Hp}$ molecules that are bonded to the surface of the Co-Cr alloy plate. Also, RAOSMC is effectively damaged and detached from surface of the Co-Cr alloy plate due to PDI. The results suggest that such ROS generated from photofunctional Co-Cr alloy plate give the possibility of such biomaterials to be used for coronary artery stent and antithrombogenic applications.

\section{Conflict of Interests}

This study does not have any financial support from the Ophire-optronics Ltd., Nova.

\section{Acknowledgments}

This study was supported by a Grant of the Korea Healthcare Technology R\&D Project, Ministry of Health, Welfare \& Family Affairs (Grant no. A085136) and the Bio \& Medical Technology Development Program of the National Research Foundation (NRF) funded by the Ministry of Education, 
Science and Technology (Grant no. 2012049727), Republic of Korea.

\section{References}

[1] M. A. F. Luciano, A. C. F. Antonio, K. S. Marcos, F. Desiderio, and C. X. M. George, "Influence of metal alloy and the profile of coronary stents in patients with multi vessel coronary disease," Clinics, vol. 66, no. 6, pp. 985-989, 2011.

[2] H. L. Philip, "Medical devices in orthopedic applications," Toxicologic Pathology, vol. 36, no. 1, pp. 85-91, 2008.

[3] L. Shi, D. O. Northwood, and C. Zhengwang, "Alloy design and microstructure of a biomedical Co-Cr alloy," Journal of Materials Science, vol. 28, no. 5, pp. 1312-1316, 1993.

[4] S. Viritpon, Y. Takayuki, K. Equo, D. Hisashi, and H. Takao, "Comparative study on torsional strength, ductility and fracture characteristics of laser-welded Ti-6Al-7Nb alloy, CP Titanium and Co-Cr alloy dental castings," Dental Materials, vol. 24, no. 6, pp. 839-845, 2008.

[5] H. C. Hsu and S. K. Yen, "Evaluation of metal ion release and corrosion resistance of $\mathrm{ZrO}_{2}$ thin coatings on the dental Co-Cr alloys," Dental Materials, vol. 14, no. 5, pp. 339-346, 1998.

[6] S. H. Teoh, Engineering Materials for Biomedical Applications, World Scientific Publishing, 2004.

[7] S. Longquan, D. O. Northwood, and C. Zhengwang, "The properties of a wrought biomedical cobalt-chromium alloy," Journal of Materials Science, vol. 29, no. 5, pp. 1233-1238, 1994.

[8] G. Mani, M. D. Feldman, D. Patel, and C. M. Agrawal, "Coronary stents: a materials perspective," Biomaterials, vol. 28, no. 9, pp. 1689-1710, 2007.

[9] R. Wessely, "New drug-eluting stent concepts," Nature Reviews Cardiology, vol. 7, no. 4, pp. 194-203, 2010.

[10] L. O. Jensen, M. Maeng, A. Kaltoft et al., "Stent thrombosis, myocardial infarction, and death after drug-eluting and baremetal stent coronary interventions," Journal of the American College of Cardiology, vol. 50, no. 5, pp. 463-470, 2007.

[11] K. Toutouzas, A. Colombo, and C. Stefanadis, "Inflammation and restenosis after percutaneous coronary interventions," European Heart Journal, vol. 25, no. 19, pp. 1679-1687, 2004.

[12] A. Mahapatro, D. M. Johnson, D. N. Patel, M. D. Feldman, A. A. Ayon, and C. M. Agrawal, "The use of alkanethiol selfassembled monolayers on 316L stainless steel for coronary artery stent nanomedicine applications: an oxidative and in vitro stability study," Nanomedicine, vol. 2, no. 3, pp. 182-190, 2006.

[13] M. N. Babapulle, L. Joseph, P. Bélisle, J. M. Brophy, and M. J. Eisenberg, "A hierarchical Bayesian meta-analysis of randomised clinical trials of drug-eluting stents," The Lancet, vol. 364, no. 9434, pp. 583-591, 2004.

[14] W. J. van der Giessen, A. M. Lincoff, R. S. Schwartz et al., "Marked inflammatory sequelae to implantation of biodegradable and nonbiodegradable polymers in porcine coronary arteries," Circulation, vol. 94, no. 7, pp. 1690-1697, 1996.

[15] J. R. Nebeker, R. Virmani, C. L. Bennett et al., "Hypersensitivity cases associated with drug-eluting coronary stents," Journal of the American College of Cardiology, vol. 47, no. 1, pp. 175-181, 2006.

[16] M. Magaraggia, A. Visonà, A. Furlan et al., "Inactivation of vascular smooth muscle cells photosensitised by liposomedelivered $\mathrm{Zn}(\mathrm{II})$-phthalocyanine," Journal of Photochemistry and Photobiology B, vol. 82, no. 1, pp. 53-58, 2006.
[17] G. R. Nigri, S. Kossodo, P. Waterman, P. Fungaloi, and G. M. LaMuraglia, "Free radical attenuation prevents thrombosis and enables photochemical inhibition of vein graft intimal hyperplasia," Journal of Vascular Surgery, vol. 39, no. 4, pp. 843849, 2004.

[18] H. H. Wasserman and R. W. Murray, "Singlet oxygen electronic structure and photosensitization," in Singlet Oxygen, chapter 1, pp. 1-33, Academic Press, New York, NY, USA, 1979.

[19] A. P. Castano, P. Mroz, and M. R. Hamblin, "Photodynamic therapy and anti-tumour immunity," Nature Reviews Cancer, vol. 6, no. 7, pp. 535-545, 2006.

[20] E. Won, L. Wise-Milestone, M. K. Akens et al., "Beyond bisphosphonates: photodynamic therapy structurally augments metastatically involved vertebrae and destroys tumor tissue," Breast Cancer Research and Treatment, vol. 124, no. 1, pp. 111$119,2010$.

[21] A. Almeida, A. Cunha, M. A. F. Faustino, A. C. Tomé, and M. G. P. M. S. Neves, "Porphyrins as antimicrobial photosensitizing agents," in Photodynamic Inactivation of Microbial Pathogens: Medical and Environmental Applications, M. R. Hamblin and G. Jori, Eds., vol. 11, chapter 5, pp. 83-160, Royal Society of Chemistry, Padova, Italy, 2011.

[22] M. Vijay, K. Ramachandran, P. V. Ananthapadmanabhan et al., "Photocatalytic inactivation of Gram-positive and Gramnegative bacteria by reactive plasma processed nanocrystalline $\mathrm{TiO}_{2}$ powder," Current Applied Physics, vol. 13, no. 3, pp. 510516, 2013.

[23] K. Sugamura and J. F. Keaney, "Reactive oxygen species in cardiovascular disease," Free Radical Biology and Medicine, vol. 51, pp. 978-992, 2011.

[24] X. F. Zhang and X. Li, "The photostability and fluorescence properties of diphenylisobenzofuran," Journal of Luminescence, vol. 131, no. 11, pp. 2263-2266, 2011.

[25] S. Surviliene, V. Jasulaitiene, A. Cesuniene, and A. LisowskaOleksiak, "The use of XPS for study of the surface layers of Cr-Co alloy electrodeposited from Cr(III) formate-urea baths," Solid State Ionics, vol. 179, no. 1-6, pp. 222-227, 2008.

[26] I. Milošev and H. H. Strehblow, "The composition of the surface passive film formed on CoCrMo alloy in simulated physiological solution," Electrochimica Acta, vol. 48, no. 19, pp. 2767-2774, 2003.

[27] D. B. Joel and Y. L. Hsin, "Changes in the surface oxide composition of $\mathrm{Co}-\mathrm{Cr}-\mathrm{Mo}$ implant alloy by macrophage cells and their released reactive chemical species," Biomaterials, vol. 25, pp. 1233-1238, 2004.

[28] P. Kubelka and F. Munk, "Ein Beitrag zur Optik der Farbanstriche: an article on optics of paint layers," Zeitschrift Fur Technische Physik, vol. 12, pp. 593-601, 1931.

[29] B. T. Holland, C. Walkup, and A. Stein, "Encapsulation, stabilization, and catalytic properties of flexible metal porphyrin complexes in MCM-41 with minimal electronic perturbation by the environment," Journal of Physical Chemistry B, vol. 102, no. 22, pp. 4301-4309, 1998.

[30] S. Subbiah and R. Mokaya, "Synthesis of transparent and ordered mesoporous silica monolithic films embedded with monomeric zinc phthalocyanine dye," Chemical Communications, vol. 9, no. 7, pp. 860-861, 2003.

[31] K. K. Wang, M. S. Jung, K. H. Choi et al., "Fabrication and photophysical properties of singlet oxygen generating nanoporous membrane," Surface and Coatings Technology, vol. 205, no. 15, pp. 3905-3908, 2011. 
[32] T. Ohyashiki, M. Nunomura, and T. Katoh, "Detection of superoxide anion radical in phospholipid liposomal membrane by fluorescence quenching method using 1,3diphenylisobenzofuran," Biochimica et Biophysica Acta, vol. 1421, no. 1, pp. 131-139, 1999.

[33] A. Gomes, E. Fernandes, and J. L. F. C. Lima, "Fluorescence probes used for detection of reactive oxygen species," Journal of Biochemical and Biophysical Methods, vol. 65, no. 2-3, pp. 4580, 2005.

[34] D. J. Granville, B. A. Cassidy, D. O. Ruehlmann et al., "Mitochondrial release of apoptosis-inducing factor and cytochrome c during smooth muscle cell apoptosis," The American Journal of Pathology, vol. 159, no. 1, pp. 305-311, 2001.

[35] M. Overhaus, J. Heckenkamp, S. Kossodo, D. Leszczynski, and G. M. LaMuraglia, "Photodynamic therapy generates a matrix barrier to invasive vascular cell migration," Circulation Research, vol. 86, no. 3, pp. 334-340, 2000. 

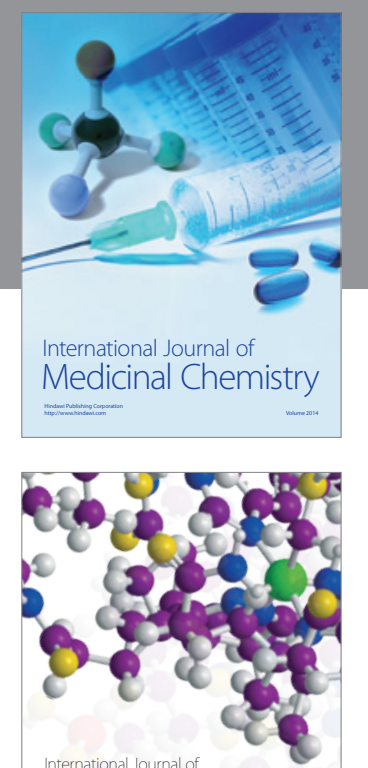

\section{Carbohydrate} Chemistry

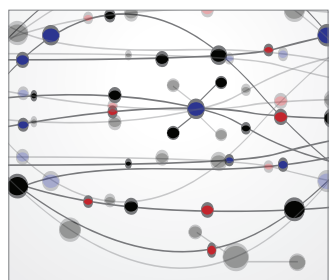

The Scientific World Journal
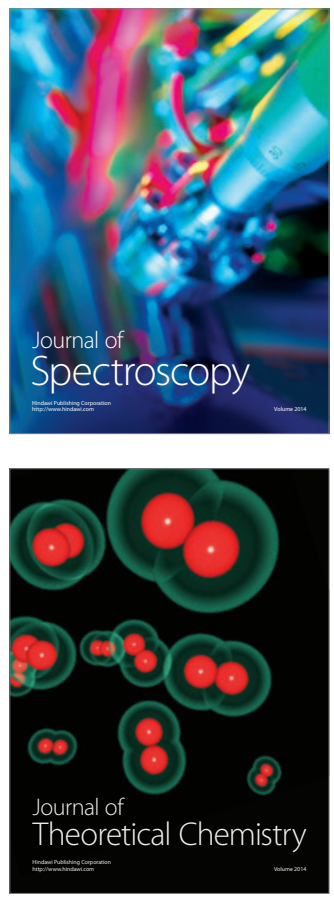
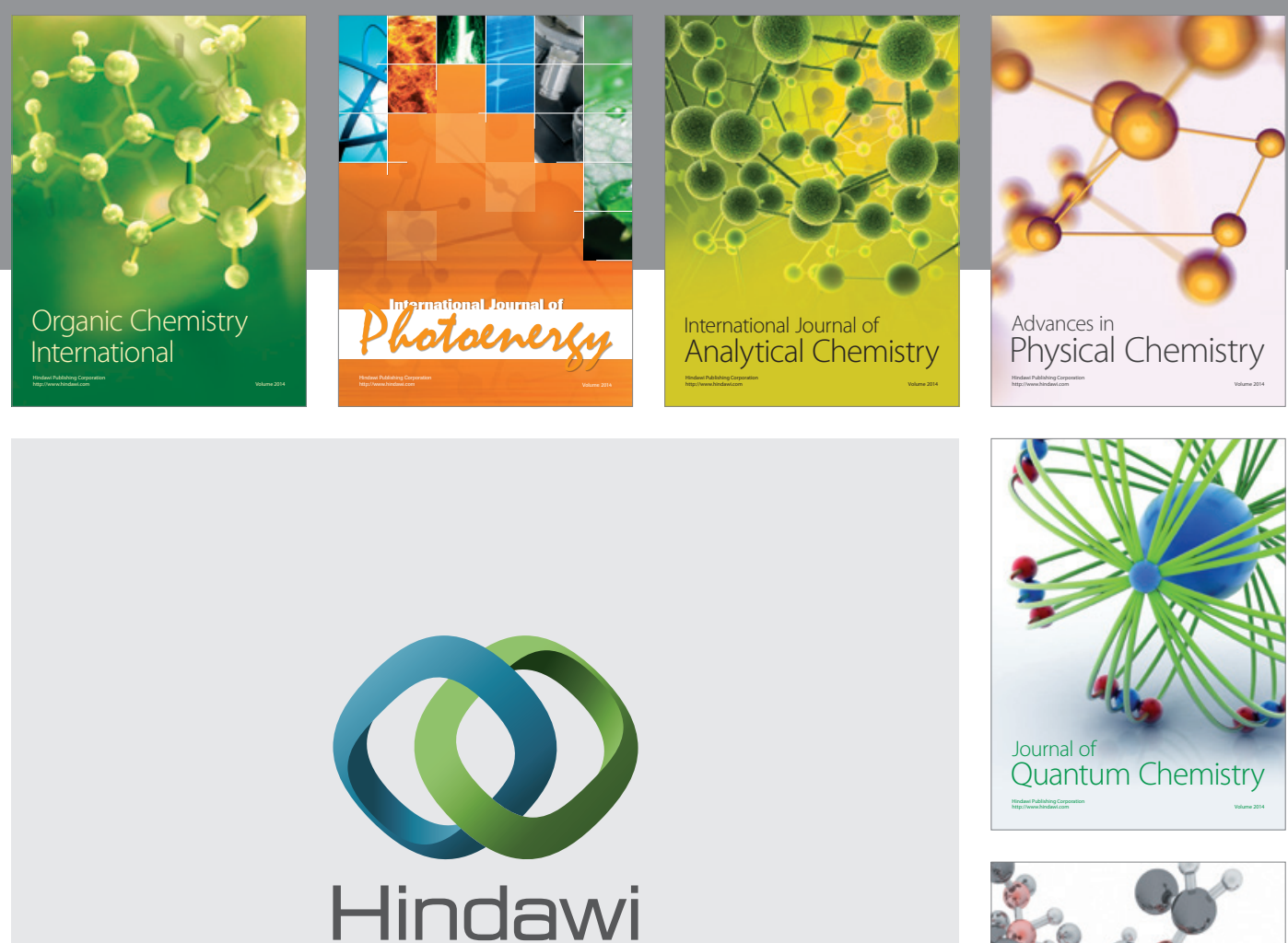

Submit your manuscripts at

http://www.hindawi.com

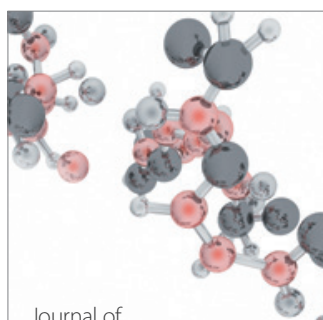

Analytical Methods

in Chemistry

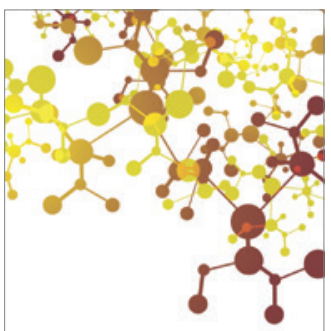

Journal of

Applied Chemistry

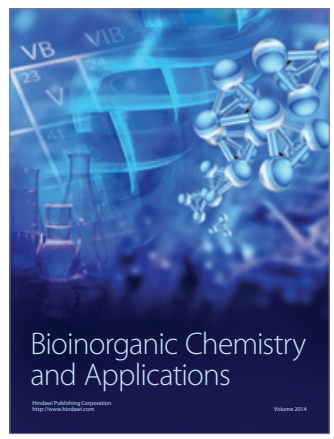

Inorganic Chemistry
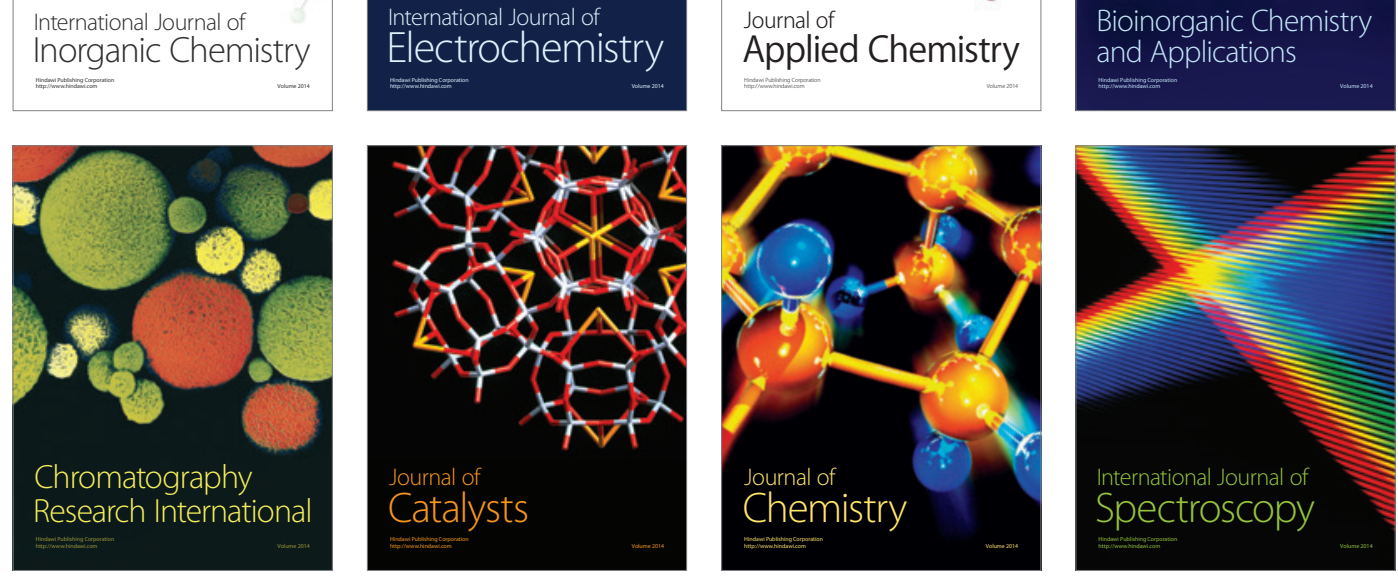